\title{
IMPORTANCE OF ECHOCARDIOGRAPHIC STRAIN IMAGING TEST FOR ASSESSMENT OF VIABILITY IN PATIENTS OF POST MYOCARDIAL INFARCTION WITH LEFT VENTRICULAR SYSTOLIC DYSFUNCTION AND ITS COMPARISON WITH SPECT
}

\author{
Amit Kumar Jha' ${ }^{1}$ S. C. Mandal ${ }^{2}$ \\ 1 Postgraduate Student, Department of Cardiology, IPGME and R, Kolkata, West Bengal, India. \\ ${ }^{2} H O D$, Department of Cardiology, IPGME and R, Kolkata, West Bengal, India.
}

\section{BACKGROUND}

ABSTRACT

Left ventricular systolic dysfunction following myocardial infarction increases risks of heart failure and sudden death. Identification of viable myocardium is important before revascularisation techniques. Therefore, in this study, we sought to explore the accuracy of resting strain to predict myocardial viability.

Aim- Myocardial deformation imaging based on strain analysis could differentiate between viable and non-viable myocardial tissue. The differentiation of viable from non-viable myocardium is therefore highly relevant in patients who are being considered for revascularisation.

\section{MATERIALS AND METHODS}

50 patients of post myocardial infarction with systolic dysfunction underwent measurement of resting strain with all 3 techniques using a 16-segment model. Strain in each coronary artery territory compare with SPECT test.

\section{RESULTS}

Post myocardial infarction with systolic dysfunction having strain value more than - $5 \%$ in particular territory, majority had nonviable myocardium in same territory. Patients with strain value between - 5 to - $15 \%$ in particular territory had variable viability, while patients with strain value less than $-15 \%$, all had viable myocardium in respective territories.

\section{CONCLUSION}

Strain analysis of myocardium is more or less well correlated with myocardial perfusion imaging test with SPECT, in predicting non-viable left ventricular myocardium.

\section{KEY WORDS}

Strain, Post MI, SPECT, Viability.

HOW TO CITE THIS ARTICLE: Jha AK, Mandal SC. Importance of echocardiographic strain imaging test for assessment of viability in patients of post myocardial infarction with left ventricular systolic dysfunction and its comparison with SPECT. J. Evolution Med. Dent. Sci. 2018;7(44):4736-4739, DOI: 10.14260/jemds/2018/1057

\section{BACKGROUND}

Coronary heart disease is a leading cause of death among men and women globally. Left ventricular systolic dysfunction is a hazardous complication of myocardial infarction that increases risks of heart failure and sudden death. The TRACE study suggested that over $50 \%$ of patients having a myocardial infarction will develop symptoms and/or signs of heart failure and in about one-third of these cases heart failure will have been present before their myocardial infarction.(1) Left ventricular function is a powerful prognostic predictor in patients with coronary artery disease. The increasing number of patients with coronary artery disease and ischaemic left ventricular dysfunction is a major clinical problem.(2)

'Financial or Other Competing Interest': None.

Submission 09-09-2018, Peer Review 10-10-2018,

Acceptance 17-10-2018, Published 29-10-2018.

Corresponding Author:

Dr. Amit Kumar Jha,

C/o. Raj Mohan Jha,

$3^{\text {rd }}$ Street, Chunapur Road,

Sipahi Tola,

Purnia-854301,

Bihar, India.

E-mail: amitdmch99@gmail.com

DOI: 10.14260/jemds/2018/1057
Potential reversibility of chronic left ventricular dysfunction is an important clinical consideration in such patients when being considered for revascularisation.

Identification of viable myocardium following myocardial infarction has gained a paramount importance with the recent progress in myocardial revascularisation techniques. Myocardial viability represents a state of impaired contractility with the potential for recovery when blood supply is adequately restored.(3) The amount of viable myocardial tissue is a potential 'surrogate' for future improvement of global left ventricular systolic function: the most powerful single predictor of long-term prognosis.

Allman et al showed that $3.2 \%$ annual death rate in patients who were considered to have viable myocardium and who underwent revascularisation compared with a $16 \%$ annual death rate in patients who had viable myocardium, but were treated medically.(4) Hence, evaluation and quantification of viable myocardium in patients of myocardial infarction with left ventricular systolic dysfunction is very important for further management of such patients.

Value of myocardial deformation parameters (Strain) in the detection of myocardial viability remains to be determined. Therefore, in this study we sought to explore the accuracy of resting strain to predict myocardial viability following myocardial infarction, taking $99 \mathrm{mTc}$ sestamibi scintigraphy as the 'gold standard' for diagnosis. 


\section{MATERIALS AND METHODS}

\section{Patient Selection and Study Design}

This is a cross-sectional observational study to explore importance use of strain echo to determine myocardial viability at low cost. We enrolled 50 patients who presented to our cardiology unit to undergo myocardial viability assessment following myocardial infarction during the period from August 2015 to October 2016. Patients were considered eligible for inclusion if they had regional wall motion abnormality in the anatomical distribution of the infarct zone as detected by resting echocardiography. We excluded patients with early post-infarction unstable angina or severe haemodynamic instability, clinically evident congestive heart failure, significant valvular or congenital heart disease, any myocardial disease apart from ischaemia, severe mitral regurgitation, atrial fibrillation and patients with limited life expectancy due to coexistent disease (For example: malignancy). Before inclusion, an informed written consent was obtained from each patient after full explanation of the study protocol.

\section{Baseline Echocardiographic Assessment}

Echocardiographic examinations were performed on the ultrasound GE Healthcare Technologies Vivid 6S, equipped with an ultrasound probe $(4 \mathrm{Mz})$ with the possibility of a complete full-fledged analysis. The patients were examined in the left lateral decubitus position at rest. Interpretation of wall motion was done in LAD, LCX and RCA territory and ejection fraction was determined. We used a semiquantitative scoring system (Normal: $\mathrm{N}$; hypokinesia: $\mathrm{H}$; akinesia: A; dyskinesia: D) for analysing each study.

\section{Strain Imaging}

Strain determined by same echo machine and patients were examined in the left lateral decubitus position with an obligatory synchronous registration of electrocardiographic lead. The standardised 17-segment left ventricle model was used for a detailed evaluation of the left ventricle segments. Parasternal projections on left ventricle long and short axis and apical 3, 2 and 4 chamber projections are taken. The software divided the left ventricle into individual segments for the specific projection. It presents an objective, semiautomatic and angle-independent analysis of strain based on speckle tracking and provides a single bull's-eye summary of the left ventricular segmental wall strain. Normal value for left ventricle average strain assessed by speckle tracking technique is in the range of - 18 to - $22 \%$. For non-viable myocardium, we take optimal cut-off value $\geq-5.3 \%$.

\section{Coronary Angiography}

Coronary angiography was done under aseptic precaution with written consent. Left coronary angiography was performed at least at four projections and right coronary angiography was performed at least at two projections. Each lesion on coronary angiogram was reviewed by two cardiologists who were blinded about the risk profile of each patient.

\section{SPECT}

Imaging identifies viable and infarcted myocardium based on regional differences in radiotracer uptake with segments classified as viable as a consequence of preserved mitochondrial function (technetium SPECT) or preserved membrane integrity (thallium SPECT). Images were interpreted by visual semi-quantitative analysis. Segmental 99mTc sestamibi uptake was scored using the five-point scoring system as follows-

- $0=$ normal uptake.

- 1 = mildly reduced uptake.

- $\quad 2$ = moderately reduced uptake.

- 3 = severely reduced uptake.

- 4 = absent uptake.

Patterns of viability were based on the segmental radioactive tracer uptake, so that segments were then individually classified into viable or non-viable. Score of 0 was considered as normal (N); 1 and 2 as viable (V); 3 and 4 as non-viable (NV).

\section{Statistical Analysis}

For statistical analysis, data were entered into a Microsoft Excel spreadsheet and then analysed by SPSS 20.0.1. Categorical variables were described with absolute and relative (percentage) frequencies by using Chi-square test. According to the above assignment of myocardial segments (viable and non-viable), S and SR were compared among the 2 groups in each individual anatomical segment. P-value $\leq 0.05$ was considered for statistical significance.

\section{RESULTS}

The mean age (mean \pm SD) of patients was $55.62 \pm 9.38$ years with range 30 to 73 years. In present study, majority of patients $(42 \%)$ had age between 51 and 60 years. Male dominate in our study with M/F ratio = 9: 1 .

\begin{tabular}{|c|c|}
\hline Variable & Mean $( \pm$ SD) or Number $(\%)$ \\
\hline Age (years) & $55.62 \pm 9.38$ \\
\hline Diabetes & $16(32 \%)$ \\
\hline Hypertension & $20(40 \%)$ \\
\hline Obesity & $15(30 \%)$ \\
\hline Smoking & $32(64 \%)$ \\
\hline Dyslipidaemia & $30(60 \%)$ \\
\hline \multicolumn{2}{|c|}{ Table 1. Baseline Characteristics of 50 Participants } \\
\hline
\end{tabular}

\begin{tabular}{|c|c|c|c|c|}
\hline \multicolumn{5}{|c|}{ Strain LAD } \\
\hline MPI LAD & A & B & N & TOTAL \\
\hline Nv & 23 & 0 & 0 & 23 \\
\hline V & 0 & 5 & 22 & 27 \\
\hline Total & 23 & 5 & 22 & 50 \\
\hline Table 2. Association between Myocardial Perfusion \\
Imaging Test (SPECT) vs. Strain in LAD Territory \\
\hline
\end{tabular}

Chi-square value: 50.0000; p-value: $<0.0001$.

\begin{tabular}{|c|c|}
\hline Group & Strain (\%) \\
\hline A & $>-5$ \\
\hline B & -5 to -15 \\
\hline N & $<-15$ \\
\hline \multicolumn{2}{|c|}{ Table 3 } \\
\hline
\end{tabular}

\begin{tabular}{|c|c|}
\hline Group & MPI \\
\hline $\mathrm{V}$ & Viable \\
\hline $\mathrm{Nv}$ & Non-viable \\
\hline \multicolumn{3}{|c|}{ Table 4 } \\
\hline
\end{tabular}


Among the total 23 patients with strain value in LAD territory $>-5 \%$, all had non-viable myocardium in same territory, while patients with strain value $<-15 \%$ all had viable myocardium in respected territory ( $p$ value $<0.001$ ). Among the total 5 patients with strain value in LAD territory between - 5 and $-15 \%$, all had viable myocardium in same territory.

\begin{tabular}{|c|c|c|c|c|}
\hline \multicolumn{5}{|c|}{ Strain LCX } \\
\hline MPI LCX & A & B & N & TOTAL \\
\hline Nv & 2 & 0 & 0 & 2 \\
\hline V & 0 & 1 & 47 & 48 \\
\hline Total & 2 & 1 & 47 & 50 \\
\hline $\begin{array}{c}\text { Table 5. Association between Myocardial Perfusion } \\
\text { Imaging Test (SPECT) vs. Strain in LCX Territory }\end{array}$ \\
\hline
\end{tabular}

Chi-square value: 50.0000; p-value: $<0.0001$.

\begin{tabular}{|c|c|}
\hline Group & Strain (\%) \\
\hline A & $>-5$ \\
\hline B & -5 to -15 \\
\hline N & $<-15$ \\
\hline \multicolumn{3}{|c|}{ Table 6 } \\
\hline
\end{tabular}

\begin{tabular}{|c|c|}
\hline Group & MPI \\
\hline V & Viable \\
\hline Nv & Non-viable \\
\hline \multicolumn{2}{|c|}{ Table 7 } \\
\hline
\end{tabular}

Among the total two patients with strain value in LCX territory $>-5 \%$, all had non-viable myocardium in same territory, while patients with strain value $<-15 \%$ all had viable myocardium in respected territory ( $\mathrm{p}$ value $<0.001$ ). One patient with strain value in LCX territory between -5 and $-15 \%$ had viable myocardium in same territory.

\begin{tabular}{|c|c|c|c|c|}
\hline \multicolumn{5}{|c|}{ Strain RCA } \\
\hline MPI RCA & A & B & N & Total \\
\hline Nv & 10 & 0 & 0 & 10 \\
\hline V & 0 & 1 & 39 & 40 \\
\hline Total & 10 & 1 & 39 & 50 \\
\hline $\begin{array}{c}\text { Table 8. Association between Myocardial Perfusion } \\
\text { Imaging Test (SPECT) vs. Strain in RCA Territory }\end{array}$ \\
\hline
\end{tabular}

Chi-square value: 50.0000; p-value: $<0.0001$.

\begin{tabular}{|c|c|}
\hline Group & Strain (\%) \\
\hline A & $>-5$ \\
\hline B & -5 to -15 \\
\hline N & $<-15$ \\
\hline \multicolumn{2}{|c|}{ Table 9 } \\
\hline
\end{tabular}

\begin{tabular}{|c|c|}
\hline Group & MPI \\
\hline $\mathrm{V}$ & Viable \\
\hline $\mathrm{Nv}$ & \multicolumn{1}{c|}{ Non-viable } \\
\hline \multicolumn{3}{|c|}{ Table 10 } \\
\hline
\end{tabular}

Among the total 10 patients with strain value in RCA territory $>-5 \%$, all had non-viable myocardium in same territory, while patients with strain value $<-15 \%$ all had viable myocardium in respected territory ( $\mathrm{p}$ value $<0.001$ ). Only one patient with strain value in RCA territory between 5 and $-15 \%$ had viable myocardium in same territory.
Myocardial infarction patients of late presentation with strain value $>-5 \%$ in particular territory, majority had nonviable myocardium in same territory, while patients with strain value $<-15 \%$, all had viable myocardium in respected territory. Strain value $>-5 \%$ in particular territory was very well correlated with non-viable myocardium in same territory as detected by myocardial perfusion test with SPECT.

\section{DISCUSSION}

Myocardial infarction patients of late presentation with strain value $>-5 \%$ in particular territory, majority had non-viable myocardium in same territory. Patients with strain value between - 5 to - $15 \%$ in particular territory had variable viability, while patients with strain value $<-15 \%$ all had viable myocardium in respected territory.

Among the total 23 patients with strain value in LAD territory $>-5 \%$ all had non-viable myocardium in same territory, while patients with strain value $<-15 \%$ all had viable myocardium in respected territory ( $p$ value $<0.001$ ). Among the total 2 patients with strain value in LCX territory >- $5 \%$ all had non-viable myocardium in same territory, while patients with strain value $<-15 \%$ all had viable myocardium in respected territory ( $\mathrm{p}$ value $<0.001$ ). Among the total 10 patients with strain value in RCA territory $>-5 \%$ all had nonviable myocardium in same territory, while patients with strain value $<-15 \%$ all had viable myocardium in respected territory ( $\mathrm{p}$ value $<0.001$ )

Cardiac gated perfusion SPECT imaging is relatively widely available and very sensitive for detecting non-viable myocardium. Rest perfusion imaging score ${ }^{(3-4)}$ evaluated in a semi-quantitative scale by means of the gated SPECT myocardium can be considered a correlate of non-viable myocardial tissue and confirming a high rest summation score represents a strongly negative prognostic predictor. $(5,6)$ Strain value for detection of myocardial viability was also seen by other studies. Roes et al (2009) showed that cut-off value of $-4.5 \%$ for regional strain discriminated between segments with viable myocardium and those with transmural scar tissue on contrast enhanced cardiac magnetic resonance with a sensitivity of $81.2 \%$ and specificity of $81.6 \%$.(7) Martin et al (2013) showed that speckle-tracking echocardiography is more accurate in predicting non-viable myocardium optimal cut-off - $5.3 \%$ identified segments with DE $>75 \%$ on contrast enhanced cardiac magnetic resonance (sensitivity $83.1 \%$, specificity $84.6 \%$ ) as compared to the rest perfusion myocardial SPECT the myocardium deformation analysis is more accurate in predicting left ventricle non-viable myocardium, which is evident on the result obtained in the area of the inferior wall corresponding to the RCA myocardium perfusion territory.(8) Nisha et al (2011), who compared global longitudinal strain with different noninvasive imaging modalities for the assessment of left ventricular function in 163 ST-elevation myocardial infarction patients. They compared global longitudinal strain with ejection fraction determined by MRI, standard echo, contrast echo, SPECT as well as with MRI-determined relative infarct size and echo determined Wall Motion Score Index (WMSI). They found that global strain is associated well with ejection fraction measured by all modalities. Global strain was found to be the best predictor of low ejection fraction 
measured by the MRI. Since global strain is an inexpensive test, these data might be of health economic interest.(9)

Grabka Marek et al (2013) assessed the predictive value of speckle-tracking echocardiography for the evaluation of infarct size in 39 patients with anterior wall ST-elevation myocardial infarction. All patients were treated with a primary PCI. On the day of discharge, speckle-tracking echocardiography was performed to determine the average global longitudinal strain of 16 myocardial segments and 9 segments supplied by LAD were assessed separately. They measured infarct size three months after ST-elevation myocardial infarction by MRI and found a significant correlation between global longitudinal strain and the degree of myocardium injury $(\mathrm{r}=0.62, \mathrm{p}=0.001)$. The correlation was higher for anterior wall global longitudinal strain $(\mathrm{r}=0.68, \mathrm{p}=0.001)$. The cut-off point for global longitudinal strain was calculated $(-12.3 \%)$, which defined a large infarct with $82 \%$ sensitivity and $87 \%$ specificity.(10)

Loic et al (2014) who assessed the value of speckle tracking imaging performed early after a first ST-elevation myocardial infarction in 44 patients to predict infarct size and functional recovery at three-month follow-up. The authors found that infarct size significantly correlated with global longitudinal strain $(\mathrm{r}=0.601, \mathrm{p}<0.001)$ and longitudinal strain was $>-6.0 \%$, within the infarcted area exhibiting $96 \%$ specificity and $61 \%$ sensitivity for predicting the persistence of akinesia (Three segments) at three-month follow-up.(11)

In present study, strain value $>-5 \%$ in particular territory was very well correlated with non-viable myocardium in same territory as detected by myocardial perfusion test with SPECT. Hence, strain derived by speckletracking echocardiography was simple, bedside and low-cost procedure for evaluation of viability of myocardium which was more or less well correlated with gold standard myocardial perfusion test with SPECT.

\section{CONCLUSION}

Myocardial deformation imaging based on strain analysis could differentiate between viable and non-viable myocardial tissue. The cut-off value of - $5 \%$ strain observed in the present study enabled the identification of non-viable segments with a high accuracy demonstrating the potential use of strain imaging for the selection of patients who will be benefited from revascularisation. Strain analysis of myocardium is more or less well correlated with myocardial perfusion imaging test with SPECT, in predicting non-viable left ventricular myocardium.

\section{REFERENCES}

[1] Kober L, Torp-Pedersen C, Jorgensen S, et al. Changes in absolute and relative importance in the prognostic value of left ventricular systolic function and congestive heart failure after acute myocardial infarction. TRACE Study Group. Trandolapril Cardiac Evaluation. Am J Cardiol 1998;81(11):1292-7.
[2] Gheorghiade M, Cody RJ, Francis GS, et al. Current medical therapy for advanced heart failure. Am Heart J 1998;135(6 Pt 2 Su):S231-S48.

[3] Hoffmann R. Stress echocardiography before and after interventional therapy. In: Marwick TH, edr. Cardiac stress testing and imaging. A clinician's guide. New York: Churchill Livingstone 1996: p. 355-67.

[4] Allman KC, Shaw LJ, Hachamovitch R, et al. Myocardial viability testing and impact of revascularization on prognosis in patients with coronary artery disease and left ventricular dysfunction: a meta-analysis. J Am Coll Cardiol 2002;39(7):1151-8.

[5] Bax JJ, van der Wall EE, Harbinson M. Radionuclide techniques for the assessment of myocardial viability and hibernation. Heart 2004;90(Suppl 5):v26-v33.

[6] Hachamovitch R, Rozanski A, Shaw LJ, et al. Impact of ischaemia and scar on the therapeutic benefit derived from myocardial revascularization vs. medical therapy among patients undergoing stress-rest myocardial perfusion scintigraphy. Eur Heart J 2011;32(8):101224.

[7] Roes SD, Mollema SA, Lamb HJ, et al. Validation of echocardiographic two-dimensional speckle tracking longitudinal strain imaging for viability assessment in patients with chronic ischemic left ventricular dysfunction and comparison with contrast-enhanced magnetic resonance imaging. Am J Cardiol 2009;104(3):312-7.

[8] Martin H, Tomas S, Milan K, et al. Speckle tracking echocardiography derived systolic longitudinal strain is better than rest single photon emission tomography perfusion imaging for nonviable myocardium identification. Biomed Pap Med Fac Univ Palacky Olomouc Czech Repub 2013;157(1):12-21.

[9] Mistry N, Beitnes J, Halvorsen S, et al. Assessment of left ventricular function in ST elevation myocardial infarction by global longitudinal strain: a comparison with ejection fraction, infarct size, and wall motion score index measured by non-invasive imaging modalities. Eur J Echocardiogr 2011;12(9):678-83.

[10] Grabka M, Wita K, Tabor Z, et al. Prediction of infarct size by speckle tracking echocardiography in patients with anterior myocardial infarction. Coron Artery Dis 2013;24(2):127-34.

[11] Loic B, Erwan D, Gwenola T, et al. Longitudinal strain is a marker of microvascular obstruction and infarct size in patients with acute ST-segment elevation myocardial infarction. PLoS One 2014;9(1):e86959. 